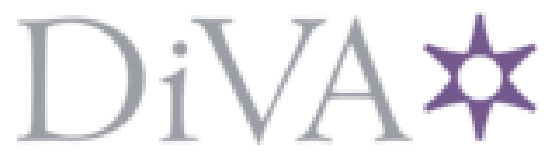

http://www.diva-portal.org

\title{
Postprint
}

This is the accepted version of a paper published in World Review of Intermodal Transportation Research (WRITR). This paper has been peer-reviewed but does not include the final publisher proofcorrections or journal pagination.

Citation for the original published paper (version of record):

Eriksson, D., Svensson, G. (2017)

Transfer of responsibility between supply chains.

World Review of Intermodal Transportation Research (WRITR), 6(2): 130-140

https://doi.org/10.1504/WRITR.2017.082730

Access to the published version may require subscription.

N.B. When citing this work, cite the original published paper.

Permanent link to this version:

http://urn.kb.se/resolve?urn=urn:nbn:se:hj:diva-35307 


\title{
Transfer of Responsibility between Supply Chains
}

\begin{abstract}
Responsibility for the environment, social, and economic issues is of rising concern for supply chain management. Even though it is acknowledged that responsibility issues extends across the entirety of the supply chain, some parts of the chain are still in need of attention. Much of the detected misconduct takes place at the beginning, or the end of the supply chain, but the end of one supply chain could actually be the beginning of another chain. Here, we shed light on the interface between such chains, an area that constitutes a blank space in research. Ship breaking is used as an empirical example, to explain one situation where materials and products at the end of their life are salvaged and enters new/other supply chains. Ship breaking has impacts on the environment and the workers, but seems to be disregarded of both the first and second supply chain. Highlighting the problem, we suggest three types of flows in and between supply chains. We also bring attention to the complexity of responsibility in, and especially between, supply chains.
\end{abstract}

Keywords

End-of-life, environmental issues, social responsibility, supply chain, sustainability 


\section{Transfer of Responsibility between Supply Chains}

\section{INTRODUCTION}

Different aspects of responsibility are growing immensely in the supply chain literature. Environmental responsibility has been emerging as an important aspect of sustainability (Winter and Knemeyer, 2013), but issues pertaining to corporate social responsibility (CSR) are claiming their territory in the discussion (Aguinis and Glavas, 2012). The discussion spans across several areas of analysis, including ethics, moral and motivation (Arnaud et al., 2013), to name a few. Much effort has been directed towards the most upstream stakeholders of the supply chain, which is reasonable as these stakeholders often have traits making it susceptible to problems (Park-Poaps and Rees, 2010).

The downstream stakeholders of supply chain are also gaining attention, but mostly for environmental aspects concerning end-of-life (when products are no longer desired by the user), for example product recovery and efficient garbage disposal. Poor environmental responsibility goes hand-in-hand with social aspects, as can be seen with how e-waste is sold to western Africa (Svensson et al., 2015).

Responsibility is often defined as a focus on economic, environmental, and social elements (Elkington, 1997), and evaluating responsibility thus calls for a balanced view across dimensions (Egilmez et al., 2013). It is not always easy to know how the economic, environmental, and social elements are interconnected, and what appears to be increased environmental responsibility can actually have dangerous effects on both the environment and people.

It is established in supply chain management (SCM) that responsibility needs to extend across the entire supply chain (e.g. Ashby et al., 2012; Wagner and Svensson, 2014). End-of-life is captivating in this aspect, as it constitutes a point where the product, or material, is no longer desired in the first supply chain, but might still hold a value if salvageable. What was at the end of one supply chain then becomes of value for a new supply chain, here referred to as a second-order supply chain.

Svensson (2007) focuses on the interconnectedness between first and second order supply chains, highlighting opportunities to reduce extraction of new materials. Recycling is important and generally seen as positive for the environment, but it can be performed in a way that negatively affects the environment, and perpetuates and exacerbates social segregation. End-of-life reveal several concerns as a result of the complexity between supply chains and within supply chains to different dimensions of responsibility, and in part as this point falls between two chains where the responsibility might be transferred from one to another supply chain. While there exists extensive research on reverse supply chains and waste management, there is a blind spot in supply chain and social responsibility research focusing on the responsibility between supply chains. To our knowledge, there is no research on intermediary points connecting chains.

The purpose here is to conceptualize to the complex management of responsibility between stakeholders in supply chains, and in particular the transfer of responsibility from one supply chain to another. 
The paper is built on illustrations of material flows inside one supply chain, between two chains, and across chains via a specific point where materials are salvaged. We especially focus on the latter type by outlining in the context of dismantled ships in Bangladesh and how the activity affects environment and workers. The case illustration is based on secondary data ${ }^{1}$. Secondary data is often necessary to use in this kind of research, as data is otherwise hard or impossible to gather properly (Punch, 1999). We consider it justifiable with this data, given that this study is mainly dedicated to bring attention to an unexplored area of research.

The case was chosen for two reasons. First, it was possible to illustrate a deficit discovered in existing theory and previous studies. Second, the case gave us an opportunity to direct the research toward a transportation audience. The conceptualization reported is derived from several years of studying responsibility in supply chains including moral responsibility in supply chains (Eriksson et al., 2013a; Eriksson et al., 2013b), social responsibility in supply chains (Eriksson and Svensson, 2015), and application of theoretical perspectives to understand responsibility in supply chains (Eriksson and Svensson, 2016b). The conceptualization reveals a deficit in existing theory and previous studies making a relevant and valuable contribution to describe non-transparency and uncertainty of transferring responsibility between supply chains.

\section{FLOWS INSIDE AND BETWEEN SUPPLY CHAINS}

This section exemplifies three situations of transfers between companies to illustrate flows (e.g. information, materials, and monetary) in and between supply chains (see also Figure 1): (i) A-flows - refers to the vertical transfer of flows from one company to another within the same supply chain; (ii) B-flows - refers to the horizontal transfer of flows from one supply chain to another, where each company has a clear role in their respective supply chain (e.g. a ship company selling one of its ships to another ship company), and (iii) C-flows - refers to horizontal transfer of flows from one chain to another, via an intermediary that does not play a clear role in either supply chain.

It is common to address these types of supply chains as 'closed-loop supply chains'. Östlin et al. (2008, p. 337) describe these as those concerned with "the flow of physical products from the manufacturer to the customer" coupled with "the [reversed] flow of used physical products from the customer, then acting as supplier, to the remanufacturer". The purpose of this article could therefore be considered to be concerned with closed-loop supply chains. The problem with using this label is that it implies a planned focus on remanufacturing that includes the original manufacturer, whereas we focus on chains where this is not done in a planned manner and we also want to focus specifically on the type of flow where one actor is situated at the end of the first and the start of the second chain. Accordingly, emphasis is here placed on C-flows of supply chains.

Insert Figure 1 about here.

The concept of flows is accepted within SCM research and can be traced back to the mid 1900s and Forrester (1958). While information, materials, and monetary flows are most

\footnotetext{
${ }^{1}$ Sample resources: http://www.vice.com/video/bangladeshi-shipbreakers-815, http://www.shipbreakingbd.info, http://ngm.nationalgeographic.com/2014/05/shipbreakers/gwin-text, http://www.theatlantic.com/photo/2014/11/the-ship-breakers/100859/, https://news.vice.com/article/visiting-the-deadly-ship-breaking-yards-of-bangladesh
} 
commonly discussed, Forrester also included flows of capital equipment and manpower. Recently, it has also been argued how moral responsibility in supply chains might be understood if considered supply chain flows (Eriksson, Hilletofth and Hilmola, 2013a; Eriksson, Hilletofth and Hilmola, 2013b). Their research shows how the structure and management of the supply chain can cause individuals' sense of moral responsibility to deteriorate. As a consequence, less attention is given to various forms of corporate misconduct.

Assigning responsibility in a supply chain is not trivial. A common view is that responsibility should be proportional to how much one contributes to injustices, but other factors such as one's connections, privilege, and power can be used to assign responsibility (Young, 2004). Here, however, the focus is on responsibility that follows the flow of the product through each pair of supplier/buyer relationships across the supply chain.

\section{A-Flows}

Supply chains are often considered the chain of actors connecting the point-of-origin (raw materials) with the point-of-consumption (end usage) (e.g. Svensson, 2007). Research focuses often on the A-flows in supply chains (i.e. the horizontal transfer of flows from one company to another within the same supply chain, so also in relation to responsibility issues (e.g. Crespin-Mazet and Dontenwill, 2012; Hoejmose and Adrien-Kirby, 2012; Saini, 2010).

A-flows in supply chains are often discussed regarding how far responsibility should expand and what the limiting factors are. Svensson (2009) argues how companies limit their range of responsibility and limit transparency. Managerial issues, such as supplier compliance to ethical guidelines are discussed (e.g. Egels-Zandén, 2007; Locke et al., 2013), highlighting the importance of considering responsibility outside of the boundaries of the own corporation (Björklund et al., 2012; Mares, 2010).

A-flows in supply chains have gained a lot of attention and it is also reasonable to assume that companies accept responsibility for their chain, and that consumers expect that companies take their share of this responsibility. Swedish fashion company Gina Tricot highlighted issues in A-flows of their supply chain in their 2012 sustainability report, focusing on the structural challenges that lies ahead, especially in the upstream supply chain (i.e. towards point-of-origin).

The downstream supply chain has not gained as much attention. Noteworthy is how a company in the pharmaceutical industry recently took downstream responsibility when they stopped prisons from using their products when administrating capital punishment (Eriksson, 2014). Given the extensive attention already given in literature to A-flows, we will not elaborate further on this topic in this paper.

\section{B-Flows}

B-flows occur at the point-of-disposal. Products that are no longer desired are sometimes transferred to a second-hand supply chain. In SCM common aspects discussed in relation to B-flows are recycling, reuse of materials, refurbishing, repair, and re-manufacturing (Stock, 1998). All of these B-flows require an approach to SCM that is wider than the definition given above, where the point-of-origin (raw-material extraction) and the point-ofconsumption (end use) set the boundaries of the supply chain and its management.

If a stakeholder-value approach is adopted, the actors in the supply chain need to extend their responsibilities and commitments to include those affected, even outside the scope of the 
chain itself (Mathur and Kenyon, 1997). Still, "SCM has evolved towards a strong vertical emphasis on the different levels within the supply chains. The horizontal levels ... are generally ignored” (Svensson, 2007, p. 264).

It should be stated that even though horizontal levels are generally ignored, they do receive attention. However, it appears that much of the attention is centered on structural challenges related to efficiency (e.g. Matsumoto and Komatsu, 2015; Savaskan et al., 2004; Östlin, Sundin and Björkman, 2008), and not so much issues concerning the transfer of responsibility between supply chains.

In contrast to A-flows of supply chains, the authors acknowledge that responsibility and the B-flows in supply chains have not received as much attention as deserved and that the area need further research. The main focus in the current paper is however on a horizontal flow between supply chains, when there is one point, placed between two supply chains, facilitating the flow from a product at the end of one supply chain (product use ended), to the start of another (product dismantling). It is here referred to as a C-flow.

\section{C-Flows}

As stated above, a C-flow is a horizontal flow between supply chains. The point of transfer is located between two supply chains enabling the flow from the end of one supply chain, to the start of the other, while still not really being involved in either of the supply chains. This disconnection can stem from several reasons, such as low transparency at the end of the supply chain, and that materials at the start of the other supply chain may be hard to trace, perhaps as a result of salvaged/scrap material being mixed with new material. As C-flows are at the center of the current paper, a case illustration will be used, namely shipbreaking in Bangladesh.

The transfer of CSR engagement between supply chains is rarely acknowledged in literature. The C-flow (i.e. horizontal transfer between supply chains) is here exemplified with ship breaking. It entails that one shipping company sells a ship to a ship breaker, from which the salvaged/scrap material is sold on and enters a new supply chain. As this is the main focus of this paper, it is expanded with an empirical example below.

\section{EMPIRICAL EXAMPLE OF A C-FLOW}

Ships can have deadweight of several thousand tons and are mainly constructed of steel, but contain other valuable resources spanning from materials (e.g. cupper), to products (e.g. furniture). The ships thus contain valuable assets even when they can no longer be used and as such they hold potential value for several industries. Moreover, the ability to harvest materials from old products is increasing in importance (cf. Graedel et al., 2015). Bangladesh is an important region to which scrap ships are sold. Even though Bangladesh is still a developing country, some indicators show improvements. The World Bank data based shows a reduction in poverty from $48.9 \%$ of the population in 2000 , to $31.5 \%$ in 2010 , and indicators for deaths among young children and fertility rates are dropping.

In Bangladesh, the ships are broken down, and the materials and parts can be recycled or reused. Workers come from the northern parts of Bangladesh to escape poverty. So far it seems to be a good way to reduce the impact on the environment, and to improve living conditions of the people, but the reality is far more nuanced. 
Workers have poor knowledge of the potential hazardous materials in the ships that are dismantled on beaches. For example, the ships contain both black oil and asbestos, which leak out into the environment. The workers do not have access to proper safety equipment, and are responsible for their clothing. The salaries are, however, so low that it is hard to just pay for living expenses, let alone safety equipment. Subsequently, the poverty is perpetuated, and the workers face health hazards.

The activity of dismantling ships contains, as indicated above, both positive and negative effects on the environment. It is hard to determine if the net-effect is positive or negative, and if such weighted measurement makes any sense at all. The effect on workers is also debatable. On one hand they are able to get employment, but on the other it might only help reinforce social problems. (Similar conundrums have been discussed by authors such as de Mesquita and Smith (2012) and Powell and Zwolinski (2012).)

Considering the size of each ship and that it is a tedious and labor-intensive task to break it down it should be easy to offer transparency for the previous ship owner to provide information about where it is being broken down. However, it is harder to trace the origin of the materials dismantled in the second order supply chain, because they are being sold on scrap heaps, and materials (e.g. steel) are melted down and mixed with materials from other sources. In this regard, the chain is here suffering the transparency problems that are present in other industries, such as textiles (Park-Poaps and Rees, 2010) and mining (Eriksson and Svensson, 2016a).

Shipbreaking is remarkable in the sense that the first supply chain is connected to the salvage/scrap of the ship, and the second chain starts where the ship is salvaged. Still, the activity of breaking the ship is not included in the responsibility boundaries (Egels-Zandén, 2015) of either supply chain. This is perhaps to expect, as transparency is low and there are several actors that can be attributed with blame (Bandura, 1999; Eriksson and Svensson, 2016b). In a B-flow of a supply chain the salvaging/scrap company would either play a clear role in the first supply chain, or in the second. For example, charity organizations that collect old clothes are also responsible for sorting and retailing, giving them a prominent role in the supply chain after the horizontal movement. Ship breakers, however, are diaphanous in both the first and second order supply chains.

\section{ASSIGNING RESPONSIBILITY}

The previous case illustration of ship breaking illustrates the non-transparency and uncertainty when it comes to the transfer of responsibility from a first order supply chain to second order supply chain. What appears to be positive in the first order supply chain for the environment can be damaging for the environment in the second order supply chain. Discussing responsibility in C-flows thus demands that the transfer point is acknowledged to have potentially both positive and negative impacts on people, profitability, and the planet.

The attention to C-flows makes it is easy to focus on the first or the second order supply chains where actors in each might claim to take environmental responsibility, but the point of transfer between the supply chains falls outside the accepted responsibility of both.

Analyzing tradeoffs in such matters is also a daunting task. The working conditions for ship breakers can at one hand make us assume that the activity is negative for the social element. 
However, allowing people to work under poor conditions in developing countries, in ways that workers in developed countries would not accept, can help under privileged to improve their situation.

Coakley and Kates (2013), as well as Powell and Zwolinski (2012), debate a similar topic, sweatshops, and whether or not it is desirable for the workers to have sweatshops regulated. It is even harder to determine if the overall activity of shipbreaking, as described above, is positive or negative if we account for both environmental and social issues. Even more so, who is responsible for the positive and negative effects?

The responsible stakeholder for the transfer through a ship breaker is not straightforward. In an A-flow responsibility issues are often hard to manage. This is partly due to the boundaries of legal influence, versus the area in which transfers take place. These boundaries are often not overlapping (Gimenez and Tachizawa, 2012).

The transfer point between first- and second-order supply chains is complicated. For example, is the owner of the ship in the first order supply chain responsible for how the ship is recycled, or if it is the responsibility of the new owner of the second order supply chain to ensure that materials that enter the supply chain are produced in a responsible manner?

It could also be argued on what basis responsibility is assigned to different actors (Young, 2004). The debate of the responsibility of the businessman traces back over fifty years (Bowen, 1953), and is still not resolved. What we do know is that structures similar to those of C-flows, where transparency is low, responsibility is uncertain, and materials from different sources are often combined, it is easy for companies to avoid or escape responsibility, and likely that individuals in the companies feel less personal responsibility for potential misconduct (Eriksson and Svensson, 2016b).

\section{CONCLUSIONS}

The purpose was to bring attention to the complexity of transferring responsibility from one supply chain to another. It was also about in the horizontal flows between supply chains that may suffer from non-transparency and uncertainty when it comes to the transfer of responsibility. This has been done by discussing three types of flows (i.e. A, B and C), focusing on the latter with the case illustration of ship breaking in Bangladesh.

We conclude that it is challenging to assess environmental and social responsibility alone, and that it is even more challenging to assess the different aspects against each other. The point of transfer between two supply chains is also problematic as it could be argued that it is better if the first-order supply chain, with more traceability, takes responsibility. The second-order supply chain has a structure that inherently complicates this task (Eriksson and Svensson, 2016b).

Moving forward from here there is a need of developing transparent measurements of responsibility. In the example of ship breaking, both positive and negative social, environmental, and economic aspects need to be included. There is also a need for both researchers and practitioners to focus on responsibility across single or multiple supply chains, which might be dependent on the ability to understand the non-transparency and uncertainty that may exist in the interface between supply chains. This specific point seems to fall between chairs, but is of importance in several industries that salvage materials and 
components for reuse (e.g. recovery and recycling of raw materials in electronic components, such as computers, mobile phones and TVs).

We argue that it is important to theorize about this specific point of transfer between supply chains. There are models in economy on how to calculate incremental costs for making a product that is a by-product of the main production, and in life-cycle analysis there are models on how to distribute shared environmental impact between the main product and a by-product. Perhaps similar models need to be developed for the transfer of responsibility between supply chains to handle the non-transparency and uncertainty?

The challenge for practitioners is an extension of current discussions on how far responsibility should extend. It is, perhaps, hard to argue that practitioners in the second supply chain should take responsibility for the first supply chain. Still, it is possible to argue that the transfer point from one chain to another should be included into the responsibility boundaries. If managers are to accept this responsibility, current knowledge and practices about raw-material extraction needs to be extended into salvaging.

Focusing on the transfer between two chains and making it a point of increased responsibility would force the first-order supply chain to rethink their production methods, materials use, and choices at end-of-life. It would also force the second-order supply chain to better monitor and control the materials and components that enter the supply chain, which helps to ensure improved responsibility in the entire second-order supply chain.

In the future, the conceptualization provided offers opportunities to incorporate more transportation-based research as to better understand the importance of paying attention to transparent and certain interfaces for responsibility. Similar research has been conducted in intermodal transportation research, which focuses on different types of transportation and their interfaces (cf. Roso, 2013).

\section{REFERENCES}

Aguinis, H. and Glavas, A. (2012) 'What We Know and Don't Know About Corporate Social Responsibility: A Review and Research Agenda', Journal of Management, Vol. 38 No. 4, pp.932-968

Arnaud, A., et al. (2013) 'The organisational climate of sustainability: a survey', World Review of Intermodal Transportation Research, Vol. 4 No. 2/3, pp.99-122

Ashby, A., et al. (2012) 'Making connections: a review of supply chain management and sustainability literature', Supply Chain Management: An International Journal, Vol. 17 No. 5, pp.497-516

Bandura, A. (1999) 'Moral Disengagement in the Perpetration of Inhumanities', Personality and Social Psychology Review, Vol. 3 No. 3, pp.193-209

Björklund, M., et al. (2012) 'Performance measurements in the greening of supply chains', Supply Chain Management: An International Journal, Vol. 17 No. 1, pp.29-39 
Bowen, H.R. (1953) Social responsibilities of the businessman, University Press, New York, NY.

Coakley, M. and Kates, M. (2013) 'The Ethical and Economic Case for Sweatshop Regulation', Journal of Business Ethics, Vol. 117 No. 3, pp.553-558

Crespin-Mazet, F. and Dontenwill, E. (2012) 'Sustainable procurement: Building legitimacy in the supply network', Journal of Purchasing \& Supply Management, Vol. 18 No. 4, pp.207-217

de Mesquita, B.B. and Smith, A. (2012) 'Aid: Blame It All on 'Easy Money", Journal of Conflict Resolution, Vol. 57 No. 3, pp.524-537

Egels-Zandén, N. (2007) 'Suppliers' Compliance with MNCs' Codes of Conduct: Behind the Scenes at Chinese Toy Suppliers', Journal of Business Ethics, Vol. 75 No. 1, pp.45-62

Egels-Zandén, N. (2015) 'Responsibility Boundaries in Global Value Chains: Supplier audit priotitizations and moral disengagement among Swedish firms', Journal of Business Ethics, pp.1-38

Egilmez, G., et al. (2013) 'Sustainability assessment of U.S. manufacturing sectors: an economic input output-based frontier approach', Journal of Cleaner Production, Vol. 53, pp.91-102

Elkington, J. (1997) Cannibals with Forks: The Triple Bottom Line of the 21st Century Business, New Society, Stony Creek, CT.

Eriksson, D. (2014) Moral (De)coupling: Moral Disengagement and Supply Chain Management. PhD Thesis, University of Borås, Borås, Sweden.

Eriksson, D., et al. (2013a) 'Linking moral disengagement to supply chain practices', World Review of Intermodal Transportation Research, Vol. 4 No. 2/3, pp.207-225

Eriksson, D., et al. (2013b) 'Supply chain configuration and moral disengagement', International Journal of Procurement Management, Vol. 6 No. 6, pp.718-736

Eriksson, D. and Svensson, G. (2015) 'Elements affecting social responsibility in supply chains', Supply Chain Management: An International Journal, Vol. 20 No. 5, pp.101122

Eriksson, D. and Svensson, G. (2016a) 'A balance model of theoretical sustainability framework and propositions', Corporate Governance, Vol. 16 No. 1, pp.21-34

Eriksson, D. and Svensson, G. (2016b) 'The Process of Responsibility, Decoupling Point, and Disengagement of Moral and Social Responsibility in Supply Chains: Empirical 
Findings and Prescriptive Thoughts', Journal of Business Ethics, Vol. 134 No. 2, pp.281-298

Forrester, J.W. (1958) 'Industrial Dynamics: A Major Breakthrough for Decision Makers', Harvard Business Review, Vol. 36 No. 4, pp.118-130

Gimenez, C. and Tachizawa, E.M. (2012) 'Extending sustainability to suppliers: a systematic literature review', Supply Chain Management: An International Journal, Vol. 17 No. 5, pp.531-543

Graedel, T.E., et al. (2015) 'On the materials basis of modern society', Proceedings of the National Academy of Sciences, Vol. 112 No. 20, pp.6295-6300

Hoejmose, S.U. and Adrien-Kirby, A.J. (2012) 'Socially and environmentally responsible procurement: A literature review and future research agenda of a managerial issue in the 21st century', Journal of Purchasing \& Supply Management, Vol. 18 No. 4, pp.232-242

Locke, R.M., et al. (2013) 'Complements or Substitutes? Private Codes, State Regulation and the Enforcement of Labour Standards in Global Supply Chains', British Journal of Industrial Relations, Vol. 51 No. 3, pp.519-552

Mares, R. (2010) 'The limits of supply chain responsibility: a critical analysis of corporate responsibility instruments', Nordic Journal of International Law, Vol. 79 No. 2, pp.193-244

Mathur, S.S. and Kenyon, A. (1997) Creating Value: Shaping Tomorrow's Business, Butterworth-Heinemann, Oxford, UK.

Matsumoto, M. and Komatsu, S. (2015) 'Demand forecasting for production planning in remanufacturing', The International Journal of Advance Manufacturing Technology, Vol. 79 No. 1-4, pp.161-175

Park-Poaps, H. and Rees, K. (2010) 'Stakeholder Forces of Socially Responsible Supply Chain Management Orientation', Journal of Business Ethics, Vol. 92 No. 2, pp.305322

Powell, B. and Zwolinski, M. (2012) 'The Ethical and Economic Case Against Sweatshop Labor: A Critical Assessment', Journal of Business Ethics, Vol. 107 No. 4, pp.449-472

Punch, M. (1999) 'Tackling Business Crime within Companies', Security Journal, Vol. 12 No. 2, pp.39-52

Roso, V. (2013) 'Sustainable intermodal transport via dry ports - importance of directional development', World Review of Intermodal Transportation Research, Vol. 4 No. 2/3, pp.140-156 
Saini, A. (2010) 'Purchasing Ethics and Inter-Organizational Buyer-Supplier Relational Determinants: A Conceptual Framework', Journal of Business Ethics, Vol. 95 No. 3, pp.439-455

Savaskan, R.C., et al. (2004) 'Closed-Loop Supply Chain Models with Product Remanufacturing', Management Science, Vol. 50 No. 2, pp.239-252

Svensson, G. (2007) 'Aspects of sustainable supply chain management (SSCM): conceptual framework and empirical example', Supply Chain Management: An International Journal, Vol. 12 No. 4, pp.262-266

Svensson, G. (2009) 'The transparency of SCM ethics: conceptual framework and empirical illustrations', Supply Chain Management: An International Journal, Vol. 14 No. 4, pp.259-269

Svensson, G., et al. (2015) 'Glocal Business Sustainability: Performance Beyond Zero!', International Journal of Procurement Management, Vol. Forthcoming issue,

Wagner, B. and Svensson, G. (2014) 'A framework to navigate sustainability in business networks', European Business Review, Vol. 26 No. 4, pp.340-367

Winter, M. and Knemeyer, M. (2013) 'Exploring the integration of sustainability and supply chain management: Current state and opportunities for future inquiry', International Journal of Physical Distribution \& Logistics Management, Vol. 43 No. 1, pp.18-38

Young, I.M. (2004) 'Responsibility and Global Labor Justice', The Journal of Political Philosophy, Vol. 12 No. 4, pp.365-388

Östlin, J., et al. (2008) 'Importance of closed-loop supply chain relationships for product remanufacturing', International Journal of Production Economics, Vol. 115 No. 2, pp.336-348 
Figure 1: Transfer of Responsibility in and between Supply Chains - A, B and C-flows

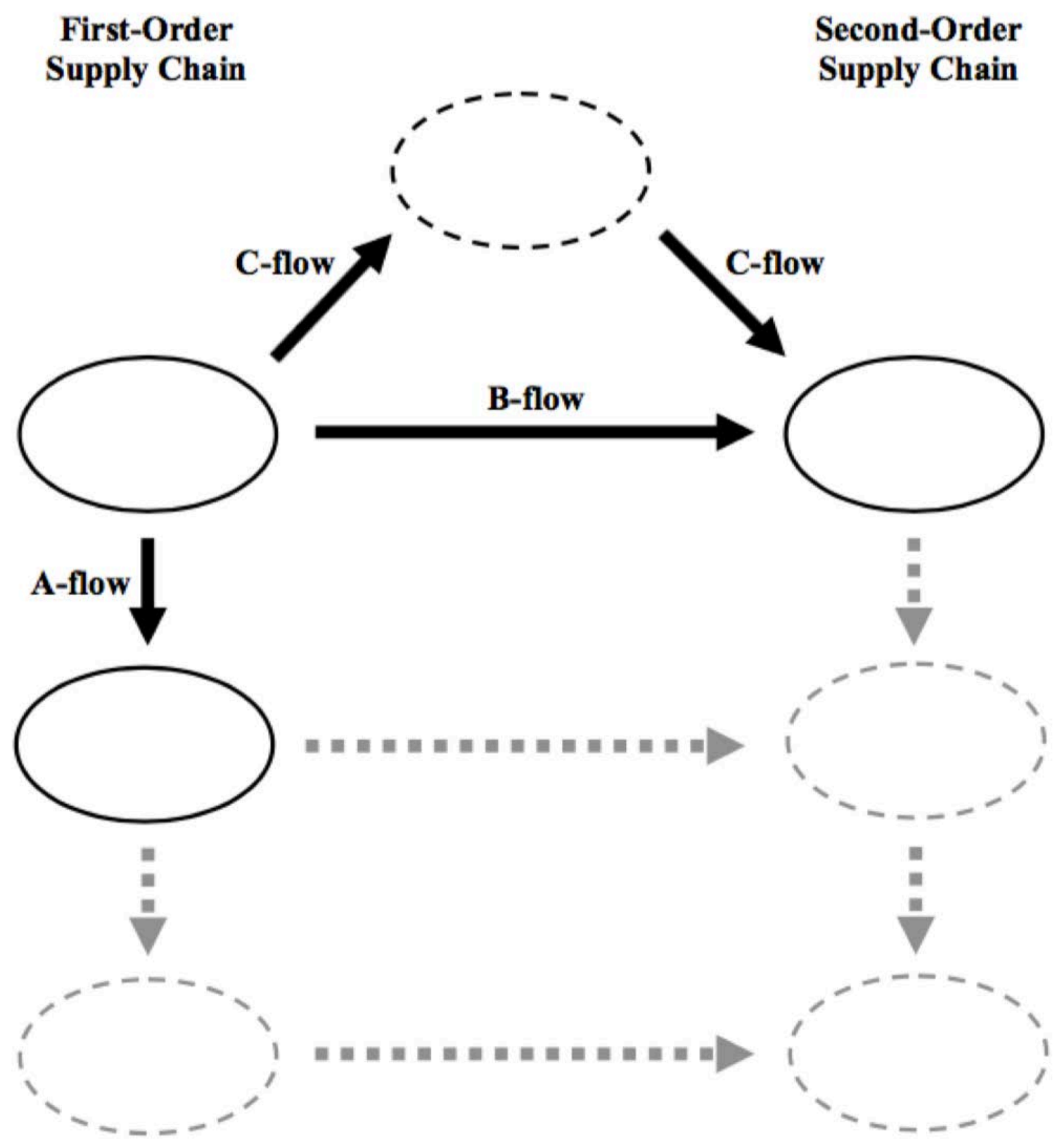

